\title{
Constitutive and Acquired Serotonin Deficiency Alters Memory and Hippocampal Synaptic Plasticity
}

\author{
Sebastian P Fernandez ${ }^{* 1,2,3}$, Aude Muzerelle ${ }^{1,2,3}$, Sophie Scotto-Lomassese ${ }^{1,2,3}$, Jacques Barik ${ }^{4}$, \\ Agnès Gruart ${ }^{5}$, José M Delgado-García ${ }^{5}$ and Patricia Gaspar ${ }^{1,2,3}$ \\ IInstitut du Fer à Moulin, Paris, France; ${ }^{2}$ INSERM, UMRS-839, Paris, France; ${ }^{3}$ University Pierre and Marie Curie, Paris, France; ${ }^{4}$ Université Côte \\ d'Azur, CNRS, IPMC, Valbonne, France; ${ }^{5}$ Division of Neurosciences, Pablo de Olavide University, Seville, Spain
}

\begin{abstract}
Serotonin (5-HT) deficiency occurs in a number of brain disorders that affect cognitive function. However, a direct causal relationship between 5-HT hypo-transmission and memory and underlying mechanisms has not been established. We used mice with a constitutive depletion of 5-HT brain levels (Pet/KO mice) to analyze the contribution of 5-HT to different forms of learning and memory. Pet/ KO mice exhibited a striking deficit in novel object recognition memory, a hippocampal-dependent task. No alterations were found in tasks for social recognition, procedural learning, or fear memory. Viral delivery of designer receptors exclusively activated by designer drugs was used to selectively silence the activity of 5-HT neurons in the raphe. Inhibition of 5-HT neurons in the median raphe, but not the dorsal raphe, was sufficient to impair object recognition in adult mice. In vivo electrophysiology in behaving mice showed that long-term potentiation in the hippocampus of 5-HT-deficient mice was altered, and administration of the 5-HTIA agonist 8-OHDPAT rescued the memory deficits. Our data suggest that hyposerotonergia selectively affects declarative hippocampal-dependent memory. Serotonergic projections from the median raphe are necessary to regulate object memory and hippocampal synaptic plasticity processes, through an inhibitory control mediated by 5 - $\mathrm{HTI}$ A receptors.

Neuropsychopharmacology (2017) 42, 512-523; doi:I0.1038/npp.2016.134; published online 31 August 2016
\end{abstract}

\section{INTRODUCTION}

Low levels of brain 5-HT, or hyposerotonergia, have long been associated with the etiology of depression and anxietyrelated disorders (Heninger et al, 1996; Jacobsen et al, 2012). The core symptomatology of these illnesses centers on mood and emotional states; however, cognitive impairment in attention and declarative memory are also prevalent (Castaneda et al, 2008; Marazziti et al, 2010; Millan et al, 2012). 5-HT deficiency has also been reported in patients with autism or with neurodegenerative brain disorders, where cognitive deficits prevail (Geldenhuys and Van der Schyf, 2011; Isoda et al, 2010; Kish et al, 2008; Scott and Deneris, 2005; Temudo et al, 2009). Clinical studies showed that enhancement of 5-HT levels by antidepressant treatment can improve cognitive performance in depressed patients, independently of any relief on other depressive symptoms (Harmer, 2008; Schmitt et al, 2006). Moreover, acute tryptophan depletion, a pharmacological approach to lower 5-HT levels temporarily applicable to both humans and rodents, impairs declarative memory (Schmitt et al, 2006; Silber and Schmitt, 2010). This evidence suggests that, independently of

* Correspondence: Dr SP Fernandez, Institut de Pharmacologie Moléculaire et Cellulaire (IPMC), Université Côte d'Azur, CNRS UMR 7275, Valbonne, 0656, France, Tel: +334939534 4l, Fax: +33 493 9534 08, E-mail: fernandez@ipmc.cnrs.fr

Received 29 March 2016; revised 7 July 2016; accepted 17 July 2016; accepted article preview online 27 July 2016 changes in mood and affective states, 5-HT deficiency could be directly involved in memory impairment by mechanisms that are still unclear.

$5-\mathrm{HT}$ is produced and released by cells located in the midbrain median raphe (MnR) and dorsal raphe (DR) nuclei (Imai et al, 1986; Jacobs and Azmitia, 1992). Through a complex and extensive axonal arborization, serotonergic neurons innervate the entire forebrain, including memoryrelated areas such as the prefrontal and entorhinal/perirhinal cortices, and the hippocampus (Imai et al, 1986; Muzerelle et al, 2016). 5-HT receptor family includes 15 subtypes widely expressed in the CNS that mediate 5-HT's inhibitory or excitatory signaling (Barnes and Sharp, 1999). A great number of preclinical studies have focused on understanding the role of specific 5-HT receptors in learning and memory processing through the use of specific agonists or antagonists drugs or the generation of knockout mouse lines (Buhot et al, 2000; Meneses, 1999). These studies have proved promising in the generation of novel target candidates for the treatment of cognitive decline (Millan et al, 2012); however, they do not adequately model the complex processes that underlie brain disorders, specifically the consequence of reducing 5-HT levels in the brain. Global changes in 5-HT brain content are difficult to manipulate and assess in humans; however, recent advances in mouse genetics allowed the generation of mouse models of 5-HT deficiency, providing novel approaches to understand the role of $5-\mathrm{HT}$ in affective behaviors and anxiety (Fernandez and Gaspar, 2012; 
Mosienko et al, 2015). Studies using these tools demonstrated that low levels of brain 5-HT are associated with increased stress reactivity and fear memory, suggesting a negative bias in information processing (Kiyasova et al, 2011; Sachs et al, 2015). Despite this evidence, the causal link between 5-HT deficiency and memory deficit, and underlying mechanisms are still unclear.

Here we used a hyposerotoninergic mouse model, the Pet1KO mice (Hendricks et al, 2003), to characterize their performance in different learning and memory tasks. We report that these mice have a specific impairment in object recognition memory but no deficits in other forms of memory such as social recognition or procedural learning. We further show that neural activity of 5-HT neurons is necessary for object memory, as it is abolished by acute silencing of the $\mathrm{MnR}$ neurons with designer receptors exclusively activated by designer drugs (DREADDs). Finally, we propose that this selective memory defect is linked to altered synaptic mechanisms in the hippocampus, based on in vivo recordings in Pet $1 \mathrm{KO}$ mice that showed altered longterm potentiation responses during the object recognition task, and that 5-HT1A receptors are crucially involved in these effects.

\section{MATERIALS AND METHODS}

\section{Behavioral Experiments}

Behavioral experiments were conducted using adult (8-12 weeks) mice weighing 30-35 g. For all experiments, male mice were used, except for experiments in Figures 3 and 4 , where male and female $\mathrm{Sert}^{\mathrm{Cre}}$ mice were used; no differences in stereotactic coordinates or behavior were observed between sexes. In all cases, animals were housed in groups of four per cage (same sex) with free access to food and water and maintained in a controlled environment $\left(20-23^{\circ} \mathrm{C}, 45-55 \%\right.$ relative humidity) with a $12 / 12 \mathrm{~h}$ light/ dark cycle (light on at 0800 hours). Animals did not undergo more than one behavioral assay. In all cases, animals were randomly allocated to experimental groups and experimenter was blind to treatment and/or genotype.

\section{Novel Object Recognition}

Novel object recognition test (NORT) was conducted in a Plexiglas arena $\left(30 \times 40 \times 40 \mathrm{~cm}^{3}\right)$. The first 2 days consisted of $30 \mathrm{~min}$ habituation sessions to the empty arena. On day 3 , two identical objects were placed in the center of the arena and animals were allowed to explore for $10 \mathrm{~min}$ (training session). After 2 or $24 \mathrm{~h}$, one object was replaced by a new one (test session). New objects were different in shape and color but made of the same material (plastic) and with similar general dimensions. New objects and positioning of new objects were counterbalanced through all experiments to avoid bias. Sessions were videorecorded by a camera placed on top of the arenas. Video tracking software (ViewPoint, France) was used to quantify locomotor activity throughout all sessions. Object exploration was scored by an experienced observer considering exploration only when mice directed their nose to the objects at a distance of no more than $2 \mathrm{~cm}$ and/or touching/sniffing the object. When mice used the object to prop themselves up to explore the environment or were accidently touching the object while headed in another direction was not computed as object exploration. In order to avoid the presence of olfactory trails, the objects and arenas were always thoroughly cleaned with ethanol $70 \%$ solution in between trials. Recognition index was computed as the time exploring the novel object divided by the total time exploring both objects and multiplied by 100 .

\section{In Vivo Field Excitatory Postsynaptic Potential (fEPSP) Recordings}

Experimental procedures used to record hippocampal fEPSP in freely moving mice have been described in detail elsewhere (Clarke et al, 2010; Gruart et al, 2006). Briefly, adult male Pet $1 \mathrm{KO}$ or control littermates mice were anesthetized with $0.8-1.5 \%$ isoflurane and implanted unilaterally with bipolar stimulating electrodes in the Schaffer collateral pathway of the dorsal hippocampus $(2 \mathrm{~mm}$ lateral and $1.5 \mathrm{~mm}$ posterior to bregma, and $1-1.5 \mathrm{~mm}$ from the brain surface (Paxinos and Franklin, 2004)) and with a recording electrode in the CA1 stratum radiatum $(1.2 \mathrm{~mm}$ lateral and $2.2 \mathrm{~mm}$ posterior to bregma and $1-1.5 \mathrm{~mm}$ from the brain surface). Electrodes were made of $50-\mu \mathrm{m}$ Teflon-coated tungsten wire (Advent Research Materials). Electrode and ground wires were soldered to a four-pin socket (RS Amidata) that was then fixed to the skull using dental cement. Animals were allowed to recover from surgery for 7 days before behavioral experiments began.

Object recognition was conducted essentially as described above; except that, in order to prevent electrical noise, the arena was inserted in a Faraday cage together with the electrophysiology equipment. During habituation, training, and test sessions, animals had their pin-sockets connected to a wire suspended above the open-field arena, which allowed us to activate and to record fEPSPs at the CA3-CA1 synapse while animals were performing the task. Before the experiment was started, fEPSPs were evoked at the CA1 area by paired ( $40-\mathrm{ms}$ interval) $100-\mu \mathrm{s}$, square, biphasic (negative-positive) pulses applied to the right Schaffer collaterals. Stimulus intensity ranged from 50 to $350 \mu \mathrm{A}$. For each animal, the stimulus intensity was set at $30-40 \%$ of the intensity necessary to evoke a maximum fEPSP response (ie, well below the threshold for evoking a population spike) and remained unchanged until the end of the experiment (Gruart et al, 2006). For the first set of experiments, baseline was obtained by recordings held on the last day of habituation to the open field. Stimuli were applied every $20 \mathrm{~s}$ for the first $5 \mathrm{~min}$ of the session $(20 \mathrm{~min})$ to evoke synaptic field potentials in the CA1. The average of these values was considered baseline for data recorded $24 \mathrm{~h}$ thereafter. During training and test sessions, home-made equipment was used to trigger hippocampal stimulation every time mice approached one object or the other with exploratory intentions (Clarke et al, 2010). In addition, a 5 -min recording sessions were conducted $5 \mathrm{~h}$ after the test session was completed to measure experience-dependent changes in synaptic strength.

For experiments involving externally induced LTP, fEPSP baseline values were recorded for $15 \mathrm{~min}$ before LTP induction. Each animal was then presented with a highfrequency stimulation (HFS) protocol consisting of five $200-\mathrm{Hz}, 100-\mathrm{ms}$ trains of pulses at a rate of one per second. 
This protocol was presented six times, at intervals of $1 \mathrm{~min}$. After HFS presentation, recordings of double-pulse stimulation at Schaffer collaterals were conducted for another $60 \mathrm{~min}$ to evaluate whether the LTP protocol was effective. On subsequent days, recordings were made for $30 \mathrm{~min}$ to assess the persistence of LTP response. All data were stored digitally on a computer through an analog/digital converter (1401 Plus; CED, England), at a sampling frequency of $11-22 \mathrm{kHz}$ and with an amplitude resolution of 12 bits. Evoked fEPSP amplitudes were analyzed offline using Spike 2 (CED). In all cases, fEPSPs were normalized and expressed as the percentage of corresponding baseline.

\section{In Vitro fEPSP Recordings}

Coronal hippocampal slices $(350 \mu \mathrm{m})$ were prepared from 6 to 8 weeks old male C57B6 mice using a vibratome (Microm HM650V, Thermo Scientific) and placed in aCSF containing (in $\mathrm{mM}$ ): 11 glucose, $2.5 \mathrm{KCl}, 26.2 \mathrm{NaHCO}_{3}, 1 \mathrm{NaH}_{2} \mathrm{PO}_{4}$, $124 \mathrm{NaCl}, 2 \mathrm{CaCl}_{2}, 2 \mathrm{MgCl}_{2}$ bubbled with a mixture of $95 \%$ $\mathrm{O}_{2} / 5 \% \mathrm{CO}_{2}$ and allowed $1 \mathrm{~h}$ to recover. fEPSPs were recorded in the stratum radiatum of the CA1 region with a borosilicate glass pipettes filled with aCSF and stimuli delivered to the Schaeffer Collateral Pathway by a bipolar tungsten electrode (WPI, Germany). Slices were visualized in a chamber on an Olympus BX51WI upright microscope and were perfused with the oxygenated aCSF at $31^{\circ} \mathrm{C}$ in the continuous presence of $100 \mu \mathrm{M}$ picrotoxin to block GABAergic function. Stimuli were delivered at $0.1 \mathrm{~Hz}$, and an input-output curve was created at the beginning of the recordings and stimulus was kept at $30-40 \%$ of maximal response. The amplitude of the fEPSP was measured and averaged baseline values were normalized to $100 \%$; subsequent values of the experiment were normalized to this baseline average (one-minute bins). 8-OH-DPAT was dissolved in water and added to the bath perfusate at a final concentration of $100 \mathrm{nM}$.

\section{Virus}

The following replication-defective adeno-associated viruses (AAV) were used: AAV8-hSyn-DIO-hM4D(Gi)-mCherry (UNC Vector Core, University of North Carolina, USA); AAV2/9-hSyn-eGFP-Cre-WPRE; and AAV2/9-hSyn-eGFPrBG (Penn Vector Core, University of Pennsylvania, USA). The titration of these AAVs was within $10^{12}-10^{13}$ viral molecules/ml.

Viruses were injected in the $\mathrm{MnR}$ ( -4.0 anterior/posterior from bregma, -1.2 medio/lateral, and -5.0 dorso/ventral) or the DR (+0.5 anterior/posterior from lambda, -0.8 medio/ lateral, and -3.2 dorso/ventral) at a volume of $300 \mathrm{nl}$. Animals were given a 3 weeks' recovery period to allow sufficient expression.

\section{RESULTS}

\section{Mice with Constitutive 5-HT Depletion Have Impaired Object Recognition Memory}

To determine whether brain 5-HT deficiency affects learning and memory processes, we used Pet1 KO mice that have an $80 \%$ depletion of brain 5-HT with no alterations of peripheral 5-HT (Hendricks et al, 2003). Adult Pet1KO and control littermates were subjected to the NORT. During training session, animals spent a similar amount of time exploring each object, yielding a recognition index of approximately $50 \%$ in both control and Pet $1 \mathrm{KO}$ mice (twoway ANOVA repeated-measures test phase $\times$ genotype, $P>0.9999$, Figure 1a). During the test session performed $2 \mathrm{~h}$ after training, control mice showed a strong preference for exploring the novel object $(\mathrm{RI}=68.9 \pm 2.7 \%$, Figure $1 \mathrm{a})$, while Pet $1 \mathrm{KO}$ mice explored equally both objects $(\mathrm{RI}=49.8$ $\pm 3.5 \%, P<0.001, n=27$ and 23 for control and Pet $1 \mathrm{KO}$, respectively). Importantly, no significant differences were observed in the total amount of time spent exploring objects $(20.87 \pm 2.36 \mathrm{~s}$ for control and $22.73 \pm 2.10 \mathrm{~s}$ for Pet $1 \mathrm{KO}$ mice). In a different cohort of animals, object recognition memory was assessed in a test session performed $24 \mathrm{~h}$ after training. As before, Pet1KO mice did not show a significant preference to explore the novel object during the test session (Figure $1 \mathrm{~b}, \mathrm{~F}_{1,22}=3.717, P>0.05$ training $v s$ test, two-way ANOVA repeated-measures and Bonferroni's multiple comparisons test). These results indicate that Pet $1 \mathrm{KO}$ mice have long-lasting impaired novel object recognition memory that can be detected as early as $2 \mathrm{~h}$ after training.

To determine whether 5-HT deficiency impairs other forms of memory, further behavioral testing was conducted. In a three-chamber social recognition test, control and Pet1KO mice spent significantly more time with a novel mouse than a familiar one previously encountered during the sociability phase, suggesting that social recognition is normal (Figure 1c). In the operant conditioning task, mice learn to associate a cue light and an operant response (nose poke) with a reward (sugar pellet). Control and Pet1KO showed an increase in the number of nose pokes in the reinforced hole $v s$ the non-reinforced across session indicating normal learning (Figure 1d). Conditioned fear memory extinction is a form of learning in which the repeated exposure to the conditioned stimulus results in an inhibition of conditioned responses. Confirming our previous observations (Kiyasova et al, 2011), we found that, after pairing a tone with a footshock, Pet1KO mice showed higher levels of freezing to the presentation of the tone alone in a new context (conditioned fear). However, extinction learning was not altered as repeated tone presentations produced a significant decrease in freezing behavior (extinction learning) in both control and Pet1KO mice (Figure 1e). Finally, motor coordination and learning was evaluated in an accelerating rotarod during 3 days of training. Again, control and Pet $1 \mathrm{KO}$ mice exhibited normal motor learning, evidenced by the longer latency to fall across the days of training (Figure 1f). Altogether, these results show that beyond object recognition 5-HT-deficient mice perform normally in other tests, suggesting that other memory systems are unaffected. In addition, it reveals that brain regions involved in object memory are a key target of cognitive defects resulting from low levels of 5-HT.

\section{Object Memory Impairment is Reversed by Increasing Brain 5-HT Levels}

Control and Pet1KO mice were injected i.p. with saline or a combination of 5-HTP $(10 \mathrm{mg} / \mathrm{kg})$ and benserazide $(20 \mathrm{mg} / \mathrm{kg})$ $30 \mathrm{~min}$ before the training and test sessions of NORT (Figure 2). The aromatic L-amino acid decarboxylase 
(AADC) inhibitor benserazide, which does not cross the blood-brain barrier, was used to prevent the 5-HT syndrome induced by 5 -HTP peripheral metabolism (Hedge et al, 1994). Thus 5-HTP is converted to 5-HT in the brain by AADC, which is widely expressed in monoaminergic and some non-monoaminergic neurons (Hökfelt et al, 1973). 5-HTP did not change object recognition in controls (RI: $67.3 \pm 2.2 \%$, vs $70.9 \pm 3.2 \% n=10$ saline and $n=16$ 5-HTP, Figure 2), whereas it significantly increased the exploration of the novel object in Pet1KO mice (RI: $53.6 \pm$ $2.2 \%$ vs $69.0 \pm 3.4 \%, \mathrm{~F}_{1,48}=10.25 P<0.01, n=11$ saline and $n=155$-HTP, Figure 2). No changes were observed in the total amount of time spent exploring the objects. These results indicate that increasing extracellular levels of $5-\mathrm{HT}$ in the brain is sufficient to normalize object recognition function in 5-HT-depleted mice.

\section{Chemogenenetic Inhibition of MnR 5-HT Cells in Adulthood is Sufficient to Impair Object Recognition}

5-HT levels in object memory-related areas are tightly regulated and depend on 5-HT neuron activity (Adell et al, 1993; McQuade and Sharp, 1997) in different raphe nuclei. In particular, 5-HT in the DR send axonal projections to cortical areas, whereas $\mathrm{MnR}$ neurons project to the hippocampus and septum (Muzerelle et al, 2016). Recent evidence has shown that the discharge of serotonergic cells is timelocked with specific cortical and hippocampal activity
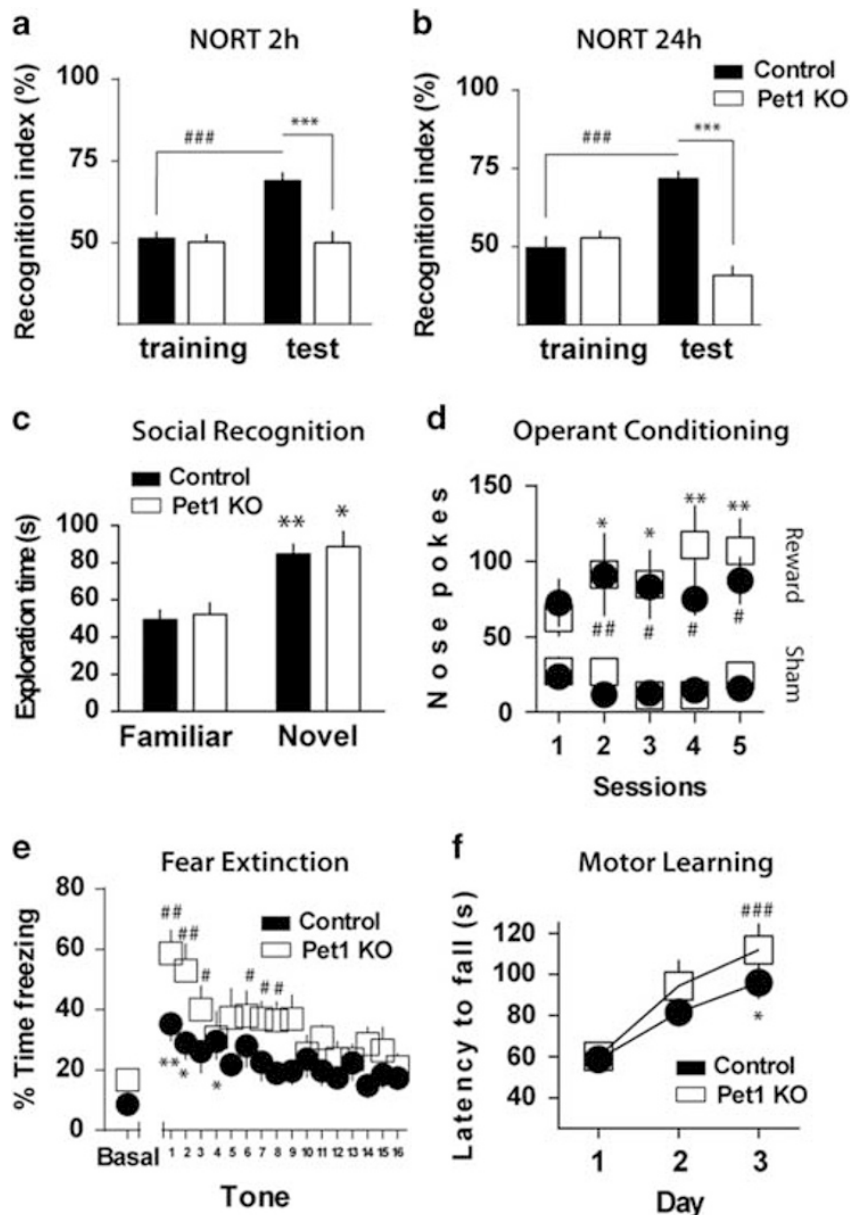

patterns (Kocsis et al, 2006; Wang et al, 2015). Therefore, we examined the effects of blocking the activity of 5-HT neurons in the two main 5-HT cells subnuclei, the MnR and the DR. For this, we stereotaxically injected AAV-hSyn-DIOhM4D-mCherry to Sert ${ }^{\text {Cre }}$ mice to selectively express the inhibitory receptor hM4D in 5-HT neurons (Figure 3a, Supplementary Figure S1). The hM4/CNO system has the advantage of allowing for reversible inhibition of cell activity (Rogan and Roth, 2011). We first confirmed that this construct was able to silence 5-HT activity using cell-attached recordings of raphe neurons in acute brain slices from hM4D-expressing mice (Figure 3c). Adding CNO to the perfusate completely blocked cell firing in transduced 5-HT neurons, which were identified by the expression of mCherry ( $n=7$, Figure 3c); notably, CNO did not affect the firing of non-transduced neurons. In a first set of

Figure I Object recognition memory, but not other forms of memory, is impaired in mice with low levels of brain 5-HT. (a) NORT was conducted with a $2 \mathrm{~h}$ delay between the training and test sessions. Recognition index is close to $50 \%$ during training sessions, indicating no bias toward any of the objects and/or locations. During the test session, control mice showed a significant preference for exploring the novel object $\left(F_{1,48}=9.925\right.$, $\# \# \#<0.00$ I training vs test and $F_{1,48}=\mid 4.92$, **** $P<0.00 \mid$ control vs PetIKO mice, Bonferroni posttest, after two-way ANOVA repeated measures), but Pet IKO failed to show this preference $(n=27$ and 23 for control and Pet/KO). (b) Similarly, when the intertrial interval was set to $24 \mathrm{~h}$, control mice showed a significant preference for exploring the novel object $\left(F_{1,22}=3.717\right.$, ${ }^{\# \# P}<0.001$ training vs test, two-way ANOVA repeated-measures and Bonferroni's multiple comparisons test). Instead, Pet/KO did not show any significant differences in exploration of objects $\left(F_{1,22}=\mid 6.41\right.$, **** $P<0.001$ control vs Pet $/ \mathrm{KO}$ mice; $F_{1,22}=3.717$ training vs test, $P>0.05$, two-way ANOVA repeated-measures and Bonferroni's multiple comparisons test, $n=13$ control and II PetIKO mice). (c) To test conspecific recognition, mice placed in a three-chamber box; the graph shows the total time spent exploring the familiar and novel mice. Control and PetIKO mice spent significantly more time with the novel mouse compared with the familiar one $\left(F_{1,80}=29.60\right.$, $* P<0.05$, ** $P<0.01$ novel vs familiar, and $F_{1,80}=0.2622, P=0.6100$ control vs Pet $/ \mathrm{KO}, n=21 /$ group). (d) Performance of control and Pet/KO mice in operant conditioning. Nose pokes on the cued hole are rewarded with sugar pellet delivery (at a fixed ratio of five pokes for one sugar pellet), while pokes on sham hole has no response. Number of nose pokes on each hole is measured across five sessions during 5 consecutive days. The increase in the number of nose pokes in the reinforced hole vs the non-reinforced one is a criterion for validating the learning of the task. Both control and Pet IKO showed normal learning $\left(F_{1,18}=24.29,{ }^{\#} P<0.05,{ }^{\#} P<0.01\right.$ rewarded $v$ s sham holes in control mice, $n=10 . F_{1,18}=12.36, * P<0.05$, $* * P<0.01$ rewarded vs sham holes in Pet IKO mice, $n=10$. Two-way ANOVA followed by Bonferroni's multiple comparison test). (e) Control and Pet / KO mice were submitted to an auditory fear conditioning and extinction protocol. Four hours after conditioning with 5 tone-footshock pairs, animals were placed in a different context and a total of 16 tones (conditioned stimulus) were presented and freezing behavior (conditioned response) quantified. Pet I KO mice showed higher levels of freezing to the presentation of the tone alone in a new context. However, extinction learning was not altered as repeated tone presentations produced a significant decrease in freezing behavior (extinction learning) in both control and Pet/KO mice $\left(F_{16}, 256=5.369\right.$, $* P<0.05$, $* * P<0.01$ vs basal freezing response in control mice, $n=9$; ${ }^{\#} P<0.05,{ }^{\#} P<0.01$ vs basal freezing response in Pet/KO mice, $n=9$. Two-way ANOVA followed by Bonferroni's multiple comparison test). (f) Control and Pet/ KO mice showed similar motor learning on the rotarod test. Latency to fall (in seconds) is shown across daily sessions. A significant increment in the latency confirms the learning of the task $\left(F_{2}, 16=19.46\right.$, $* P<0.05$ day I vs day 3 in control mice, $n=5 ;{ }^{*} \#+0.00$ I day I vs day 3 in Pet I KO mice, $n=5$. Two-way ANOVA followed by Bonferroni's multiple comparison test). All plots depict mean \pm SEM. 

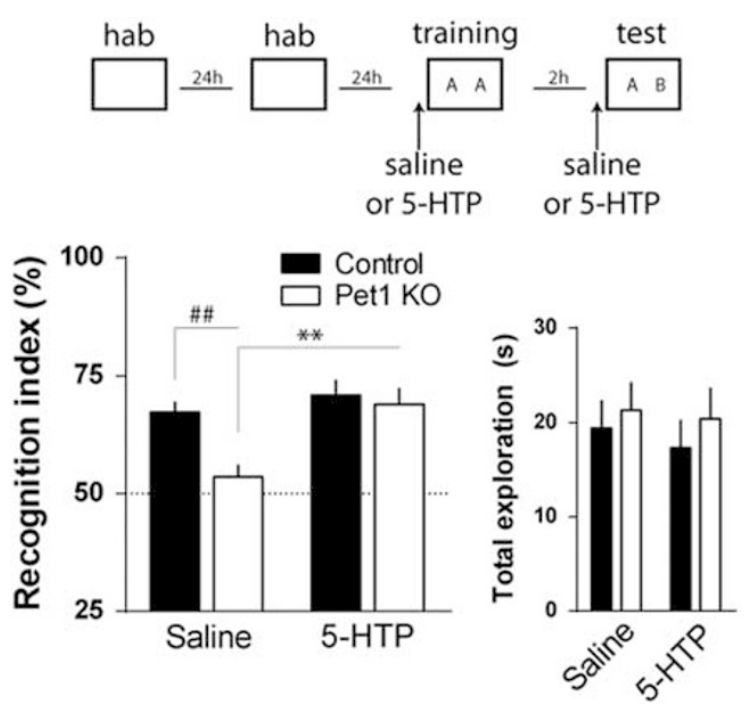

Figure 2 Increasing 5-HT levels in the brain rescues memory impairment in Pet IKO mice. Animals were injected i.p. with saline or a combination of 5-HTP $(10 \mathrm{mg} / \mathrm{kg})$ and benserazide $(20 \mathrm{mg} / \mathrm{kg}) 30 \mathrm{~min}$ before the training and test sessions. Control mice did not show changes in object recognition after drug treatment $\left(F_{1,48}=10.25, P>0.05\right.$, saline vs 5-HTP two-way ANOVA and Bonferroni's multiple comparison test). Pet IKO treated with saline showed object memory impairment $\left(F_{I}, 48=6.919\right.$, \#\# $P<0.01$, control vs Pet/KO mice), which was reversed by treatment with 5-HTP $\left(F_{1}, \quad 48=10.25\right.$, $* * P<0.01$, saline vs 5-HTP two-way ANOVA and Bonferroni's multiple comparison test). Drug treatment did not affect the total amount of time exploring the objects. Mice per group were as follows: control: 16 for saline and 10 for 5-HTP; Pet IKO: 11 for saline and 15 for 5-HTP. All plots depict mean \pm SEM.

experiments, control and hM4D-expressing mice injected in the $\mathrm{MnR}$ were subjected to NORT. CNO $(0.5 \mathrm{mg} / \mathrm{kg})$ or saline were administered i.p. on the 2 habituation days and $30 \mathrm{~min}$ before the training and test sessions (Figure $3 \mathrm{~b}$ ). Two weeks after, the same virus-transduced mice were used for a second experiment of NORT, where saline-treated mice were injected with $\mathrm{CNO}$ and vice versa. The results depicted in Figure $3 \mathrm{~d}$ show the recognition index of control and hM4Dexpressing mice after saline or CNO treatment. Control mice' performance in the NORT was not modified by either treatment (Figure 3d, $P>0.05, n=14$ mice); however, silencing 5-HT neurons in the MnR impaired object memory as demonstrated by the effects of CNO injection on the preference for the novel object in hM4D-expressing mice (Figure 3d, two-way ANOVA repeated-measures $\mathrm{F}_{1,35}=22.84,{ }^{* * *} P<0.001$ saline $v s \mathrm{CNO}$ in $\mathrm{hM} 4 \mathrm{D}$ mice, $n=23$ ). Importantly, memory impairment was not associated with changes in the total amount of exploration of objects (Figure 3d) or in ambulatory activity (Figure 3e). Expression of hM4D in Sert ${ }^{\text {Cre }}$ mice extended over the entire rostro-caudal axis of the MnR (Supplementary Figure S2). Expression outside the MnR was scarce owing to the lack of Sert ${ }^{\text {Cre }}$-expressing neurons outside the raphe in adults. In a second cohort of mice, AAV injections in Sert ${ }^{\text {Cre }}$ mice were directed to the DR, and after recovery, mice were submitted to the same NORT protocol. Inhibition of DR 5-HT neurons did not affect object recognition memory (Figure 3f) nor did it produce significant changes in ambulatory activity (Figure 3g). Altogether, these results integrate the MnR serotonergic projections to the circuitry involved in object recognition memory.

A second experimental strategy was used to chronically deplete 5-HT from the MnR to corroborate our previous results. VMAT2f/f mice were injected with AAV-eGFP-Cre in the $\mathrm{MnR}$ to disrupt monoamine vesicular transporter expression. In the absence of Vmat2, cytosolic 5-HT is rapidly degraded and the result is a striking decrease in 5-HT tissue levels (Narboux-Nême et al, 2011). Mice injected with AAV-eGFP served as controls and showed normal levels of preference for the novel object in the object recognition task (Supplementary Figure S3). Cre-injected mice, instead, showed no preference for the novel object, indicating memory deficit (Supplementary Figure S3). This result confirmed that depleting 5-HT in MnR neurons is sufficient to impair object memory.

\section{Timing of Chemogenetic Inhibition Shows Requirement of 5-HT Cell Activity During Encoding and/or Consolidation but not Retrieval of Object Memory}

In order to test which phases of memory are affected by 5-HT cell inhibition, we used Sert ${ }^{\text {Cre }}$ mice stereotaxically injected, as described above, with AAV-hSyn-DIO-hM4DmCherry in the MnR. In a first experiment, mice subjected to NORT were divided into saline and CNO groups, and a single injection was given $30 \mathrm{~min}$ before the training session (Figure 4a). Injection of $\mathrm{CNO}$ did not affect exploration of objects in the training phase, but it completely blocked preference for the novel object during the test phase (Figure 4a, two-way ANOVA repeated-measures $\mathrm{F}_{1,21}=39.95,{ }^{\# \# \#} P<0.001$ two-way ANOVA saline $\times \mathrm{CNO}$, $n=11$ and 12 for saline and CNO, respectively).

A second experiment was conducted where $\mathrm{CNO}$ was administered only before the test session (Figure $4 b$ ). In this case, both the saline- and CNO-treated groups showed a significant preference for exploring the novel object during the test session (Figure $4 \mathrm{~b}$, two-way ANOVA repeatedmeasures $\mathrm{F}_{1,20}=137.3,{ }^{* *} P<0.001$ two-way ANOVA training $\times$ test, $n=11$ /group). This experiment indicated that the activity of MnR 5-HT neurons is required during the learning phase of NORT but not during memory retrieval.

\section{LTP is Exaggerated in 5-HT-Deficient Mice}

One of the main projection targets of MnR 5-HT neurons is the hippocampus (Muzerelle et al, 2016; Vertes et al, 1999), a structure involved in object recognition (Cohen et al, 2013). To examine whether low brain levels of 5-HT could result in abnormal synaptic function in this structure, we used Pet1KO mice in which the hippocampus is completely depleted of 5-HT fibers (Kiyasova et al, 2011). Control and Pet1KO mice were implanted with electrodes to stimulate and record the CA3 and CA1 regions of the hippocampus, respectively, while the animals perform the object recognition task. It was previously shown that NORT induces changes in synaptic strength and that long-term potentiation of this synapse is required to acquire object memory (Clarke et al, 2010). Once recovered from surgery, mice were subjected to NORT and fEPSPs were recorded during the task. After establishing a baseline recording during the second day of habituation, we evaluated changes in fEPSPs 
a

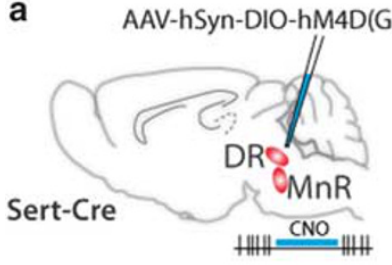

b

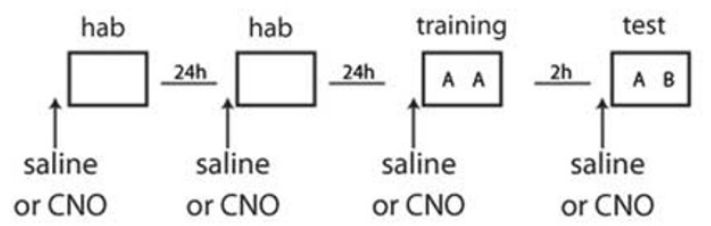

C
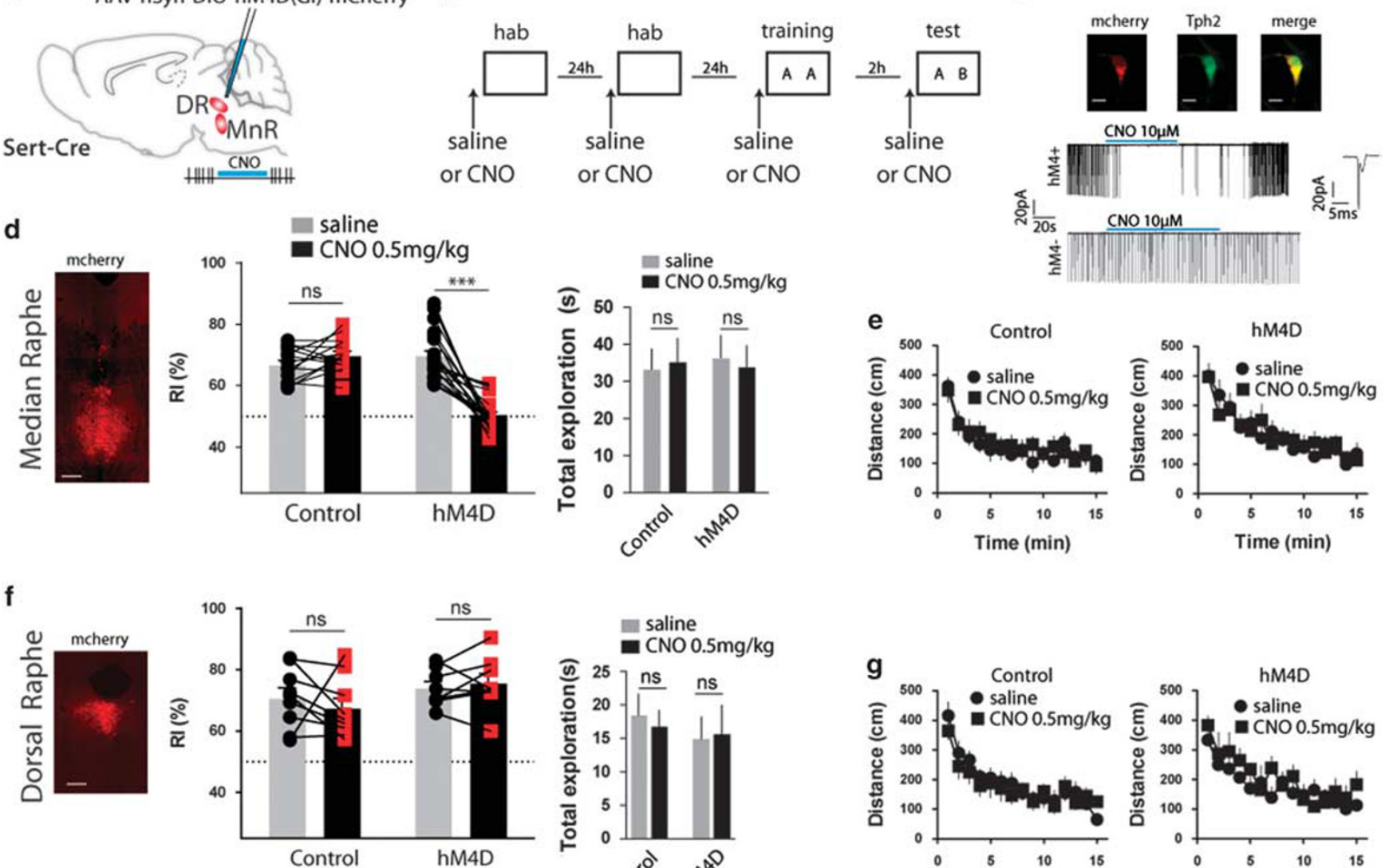
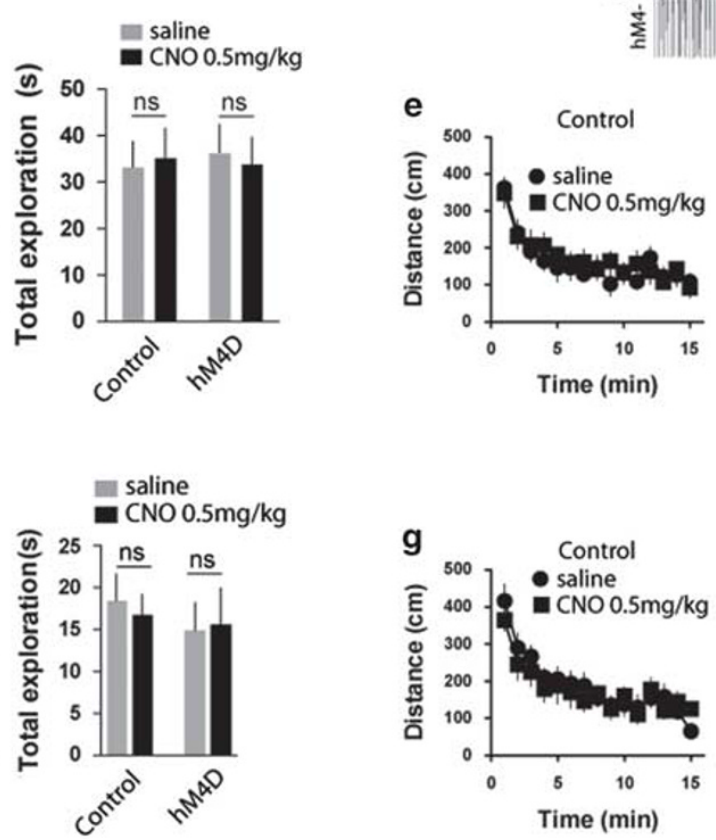

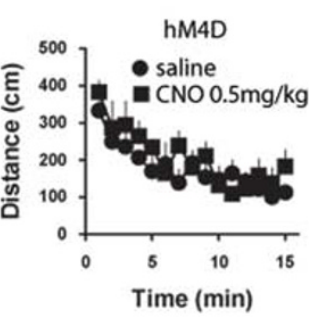

Figure 3 Chemogenetic inhibition of MnR 5-HT cells is sufficient to induce object recognition deficits in mice. (a) Injection of Sert ${ }^{\text {Cre }}$ mice with AAV8hSyn-DIO-hM4D(Gi)-mCherry into the MnR or the DR. (b) Protocol to remotely control the activity of 5-HT neurons during object recognition. CNO $(0.5 \mathrm{mg} / \mathrm{kg})$ or saline were administered i.p. on each habituation day and $30 \mathrm{~min}$ before the training and test sessions. (c) The ability of the hM4D/CNO system to inhibit the firing of 5-HT neurons was asserted using in vitro cell-attached recordings in brain slices from stereotaxically injected mice. In 5-HT neurons (green) expressing hM4D-mCherry (red), bath application of CNO (IO $\mu \mathrm{M})$ completely abolished cell discharge of action potential currents, while hM4Dnegative cells do not respond to CNO (representative current traces are shown at the bottom of the panel). (d) Control and hM4D-expressing mice injected in the $\mathrm{MnR}$ were subjected to NORT. A representative image shows the expression of mCherry in the MnR of Sert ${ }^{\text {Cre }}$ mice (scale bar $\left.=200 \mu m\right)$. CNO treatment significantly reduced preference for exploring the novel object in $h M 4 D$ mice $\left(F_{1,35}=22.84\right.$, $* * * P<0.00$ I saline vs CNO $h M 4 D$ mice $n=23$ Bonferroni posttest, after two-way ANOVA). Control mice did not show any changes in response to either saline or CNO treatments and performed normally $(P>0.05$, saline vs $C N O$ control mice $n=14)$. The total amount of time exploring the objects did not change between groups. (e) Silencing of MnR 5-HT neurons with the hM4D/CNO system did not affect locomotor activity. (f) Control and hM4D-expressing mice injected in the DR were subjected to NORT. A representative image shows the expression of mCherry in the DR of Sert ${ }^{\text {Cre }}$ mice after AAV injection (scale bar $\left.=250 \mu \mathrm{m}\right)$. Inhibition of DR serotonergic neurons did not affect object memory performance $\left(F_{1,15}=0.1209, P=0.7329\right.$, for treatment after two-way ANOVA, $n=9$ and 8 mice for control and hM4D, respectively) or total amount of time exploring the objects. (g) No effect on locomotor activity was observed after inhibition of 5-HT cells in the DR with the hM4D/CNO system.

during the training and the test sessions and $5 \mathrm{~h}$ after NORT was completed (Figure 5a). During training, no significant changes were observed in the amplitude of the fEPSPs in both control and Pet $1 \mathrm{KO}$ mice while exploring the objects (Figure 5a). During memory retention test, assessed $2 \mathrm{~h}$ after training, we observed a slight increase in fEPSP amplitude in control mice (116.2 $\pm 10.4 \%, n=10, P>0.05$, vs baseline), while this effect was more pronounced in Pet $1 \mathrm{KO}$ mice $(136.8 \pm 5.8 \%, n=9, P<0.05$, vs baseline, Figure 5a). Late changes in synaptic strength were evaluated $5 \mathrm{~h}$ after completing the NORT. We observed a $30.6 \pm 5.6 \%$ increase in evoked fEPSP in control mice compared with baseline; however, this effect was strikingly bigger in Pet $1 \mathrm{KO}$ mice $(179.5 \pm 10.5 \%, P<0.01$ vs baseline and vs control mice, Figure 5a). Pet $1 \mathrm{KO}$ mice with implanted electrodes fail to show preference for the new object in the NORT, indicating memory deficits (Figure 5a); implantation of electrodes did not modify NORT performance in control mice. None of the recorded changes in fEPSP was accompanied by a significant alteration in the hippocampal theta or gamma rhythms, indicating that all data were collected from similar alertness states (Supplementary Figure S4).

LTP in CA1 can be artificially induced by delivering HFS to the CA3 pathway, and we determined whether this form of synaptic plasticity was also affected in hyposerotonergic mice. After establishing a stable baseline, mice received one session of HFS and fEPSP amplitude was monitored every day for 4 days (Figure 5b). LTP in CA3-CA1 synapses was evident in control mice at day 1 immediately after HFS, reaching approximately 90\% increase in fEPSP amplitude and slowly decreasing to baseline levels over the course of 4 days (Figure 5b). Instead, the same HFS protocol evoked 

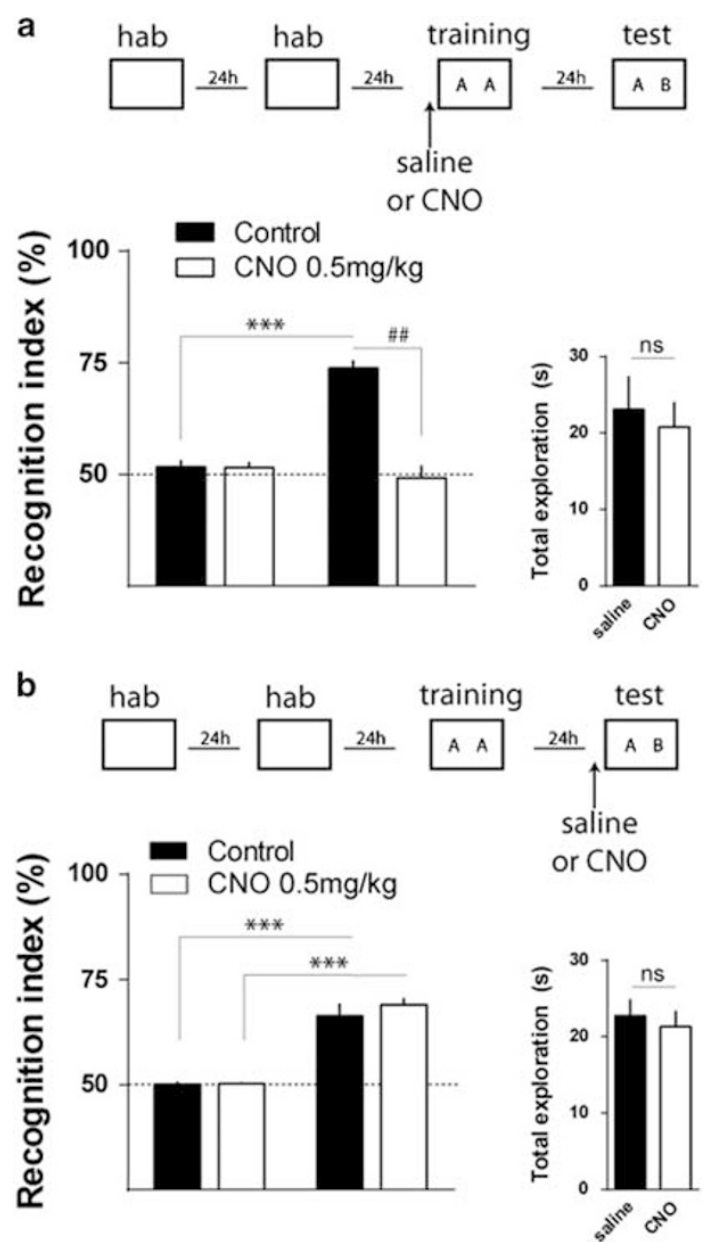

Figure 4 Chemogenetic inhibition of MnR 5-HT cells affects encoding/ consolidation but not retrieval of object memory. (a) Sert ${ }^{\text {Cre }}$ mice stereotaxically injected with AAV-hSyn-DIO-hM4D-mCherry in the MnR were used for NORT. CNO or saline were given i.p. before the training session, and a test session was conducted $24 \mathrm{~h}$ later. Saline-treated mice showed a significant preference for exploring the novel object $\left(F_{1,2 l}=26.37\right.$, **** $P<0.001$ two-way ANOVA training $\times$ test, $\left.n=1 \mathrm{I}\right)$. Injection of $\mathrm{CNO}$ did not affect exploration of objects on the training phase, but it completely blocked preference for the novel object during the test phase $\left(F_{1,21}=39.95,{ }^{\# \#} P<0.001\right.$ two-way ANOVA saline $\times C N O, n=11$ and 12 for saline and $C N O$, respectively). (b) In a second experiment, mice were given saline or $\mathrm{CNO}$ before the test session only. Both the saline and $\mathrm{CNO}$-treated groups showed a significant preference for exploring the novel object during the test session (Figure $4 B, F_{1}, 20=137.3$, *** $P<0.00 \mid$ two-way ANOVA training $\times$ test, $n=1 \mid$ /group). In both cases, total time exploring the objects were not changed. All plots depict mean \pm SEM.

higher levels of LTP in Pet $1 \mathrm{KO}$ mice reaching $>150 \%$ increase in fEPSP amplitude (Figure 5b); 3 days after HFS, Pet1KO mice still presented significant potentiation of synaptic strength in the CA3-CA1 synapse. These results indicate that in Pet $1 \mathrm{KO}$ mice LTP mechanisms are altered, likely at the postsynaptic levels as in vivo paired-pulse facilitation, a presynaptic short-term potentiation, was normal in these mice (Supplementary Figure S4). Overall these results showed that mice with low brain 5-HT level have exaggerated LTP in the hippocampus and in particular enhanced excitatory responses in CA1 neurons in response to the stimulation of Schaffer collaterals.

\section{5-HT1A Receptors Mediate Inhibitory Control Over the CA3 $\rightarrow$ CA1 Hippocampal Pathway}

We hypothesized that 5-HT release in the hippocampus participates in normal memory function through an inhibitory control of CA1 neurons. 5-HT1A receptor is one of the main inhibitory receptors expressed in the hippocampus, and a high intensity of 5-HT1A transcript can be observed in the pyramidal neurons of the CA1 region (Figure 6a). We tested the implication of this receptor in shaping the response of the CA3-CA1 hippocampal circuit on slice preparations from wild-type mice. CA1-evoked fEPSP were recorded in response to CA3 afferent stimulation (Figure 6a), and changes in fEPSP amplitude were recorded while applying the 5-HT1A receptor agonist 8-OH-DPAT $(100 \mathrm{nM})$ to the bath. After a 10 min perfusion of the drug, we observed a $45 \%$ reduction in fEPSP amplitude compared with baseline (Figure 6a). This effect was reversible as a $10 \mathrm{~min}$ wash-off period was sufficient to return to baseline levels.

We then tested whether the inhibitory action of the 5-HT1A agonist, 8-OH-DPAT, on the CA3-CA1 synapse could normalize memory function induced by $5-\mathrm{HT}$ deficiency. Pet $1 \mathrm{KO}$ and control mice were injected with 8-OH-DPAT $(0.5 \mathrm{mg} / \mathrm{kg})$ or saline $30 \mathrm{~min}$ before the training and test sessions of NORT (Figure 6b). Pet1 KO mice treated with 8-OH-DPAT showed a significant preference for exploring the novel object while the saline-treated mice did not (Figure 6b, $P<0.05, n=14$ in saline and 14 in $8-\mathrm{OH}$ DPAT groups). Instead, 8-OH-DPAT was without effects in control mice (Figure 6b, $P>0.05, n=13$ /group). Drug treatment did not affect the total amount of time exploring the objects or the locomotor activity during the test (Figure 6b).

\section{DISCUSSION}

The present results demonstrate a direct link between low levels of brain 5-HT and a specific cognitive impairment in object recognition, which is considered to be a rodent equivalent of declarative memory in humans. We show that neural activity of the medial rather than DR neurons is required for this effect. In addition, activity of 5-HT MnR neurons is required for encoding/consolidation but not for recall of object memory. Finally, we uncover a cellular and molecular target by showing that 5-HT1A receptors are required to moderate the excitatory drive in the CA3-CA1 neural circuit and that activation of $5-\mathrm{HT} 1 \mathrm{~A}$ receptors is sufficient to restore memory defects in hyposerotonergic mice. Thus 5-HT has an important role in maintaining an adequate signal-to-noise ratio in this hippocampal circuit, a necessary condition for novel object learning.

Learning and memory function is a complex phenomenon that is often categorized into different memory types, eg, declarative $v s$ non-declarative, which involve different brain regions and/or physiological processes (Squire and Zola, 1996). Therefore, defining the precise nature of changes in cognitive defects is challenging. We selected a series of behavioral tasks that allowed us to test these different memory systems and how they are affected by low brain levels of $5-\mathrm{HT}$. The object recognition test is a stress-free memory task that is dependent on the hippocampus (Clarke et al, 2010; Cohen et al, 2013; Kinnavane et al, 2015; Manns and 
a
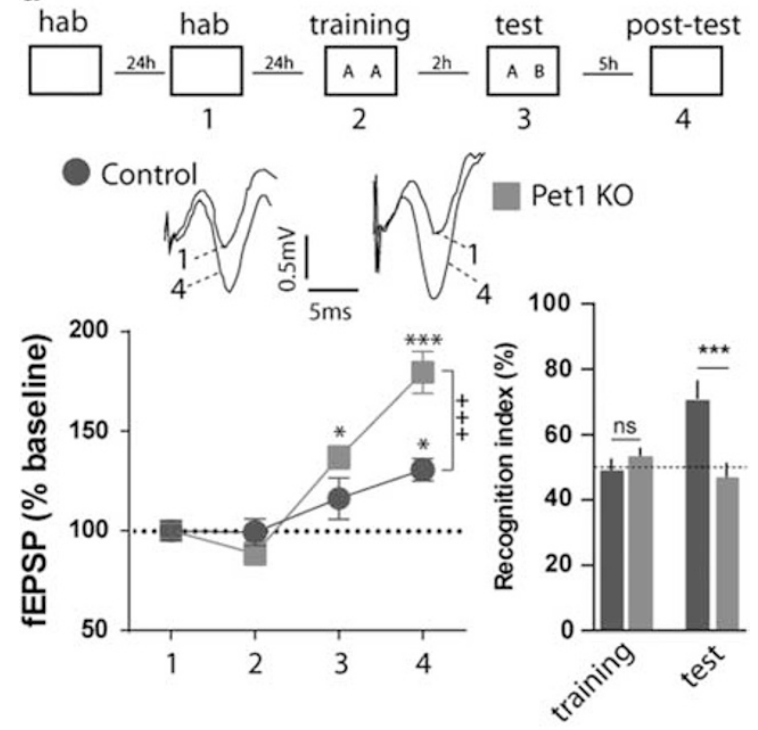

b

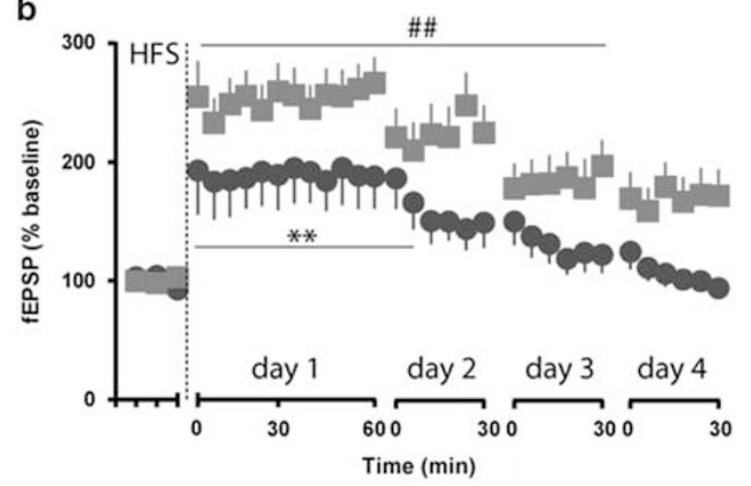

Figure 5 5-HT brain deficiency leads to exaggerated synaptic potentiation of the CA3 $\rightarrow$ CAI pathway in the hippocampus. (a) Electrodeimplanted control and Pet/KO mice were submitted to the NORT as depicted. fEPSPs were recorded after stimulation of Schaffer collaterals throughout the entire behavioral experiments. Baseline recordings were obtained during the last habituation session (I), and changes in synaptic strength were scored during object memory training (2), retention test (3), and $5 \mathrm{~h}$ after completing the task (4). Representative fEPSP traces are shown depicting baseline and posttest recordings for control and Pet I KO mice. No changes in fEPSP amplitude were observed during training (2). During the retention session conducted $2 \mathrm{~h}$ after (3), we observed a slight increase in control mice ( $\mid 16.2 \pm 10.4 \%, * P>0.05$, vs baseline), and this effect was more pronounced in Pet/KO mice (I36.8 $\pm 5.8 \%$, *P<0.05, vs baseline). Late changes in synaptic strength were evaluated $5 \mathrm{~h}$ after completing NORT (4). In control mice, LTP increased slightly (I $30.6 \pm 5.6 \%, P<0.05$, vs baseline), while we observed a striking increase in LTP in Pet/KO mice $\left(179.5 \pm 10.5 \%, \quad F_{1,1263}=3.357, \quad * * * * P<0.01\right.$ vs baseline; $F_{3,1263}=12.18$, $+++P<0.001$ vs control mice, $n=10$ control and $9 P e t / K O)$. (b) In a separate experiment, we followed the evolution of fEPSPs evoked in the CAI area after applying HFS to induce LTP. After establishing a stable baseline, five 200- Hz, I00-ms trains of pulses at a rate of one per second were applied, and this protocol was presented six times, at intervals of I min. This protocol induced a long-lasting potentiation of fEPSPs in control mice, reaching significant higher values during day $\mathrm{I}$ and the start of day 2 $(* * P<0.01$ compared with baseline in control mice, $n=10)$. Pet / KO mice showed higher levels of potentiation throughout the experiment $\left({ }^{\# \#} P<0.01\right.$ compared with baseline in Pet $K O$ mice, $\left.n=9\right)$. All plots depict mean \pm SEM.
Eichenbaum, 2009), and we show here that it is impaired in mice with 5-HT deficiency. It turn, these mice performed normally when the task involved the recognition of a conspecific. Social recognition is a unique form of memory that utilizes distinct neural system than object recognition. The emotional component of the task likely involves the mesolimbic dopamine system and the neuropeptide systems for oxytocin and vasopressin (Bielsky and Young, 2004). Procedural memory systems such as those involved in operant conditioning and motor learning are controlled by the cerebral cortex, basal ganglia, and cerebellum (Balleine et al, 2009; Hikosaka et al, 1999) and were not impaired in Pet1KO mice. Amygdala-dependent Pavlovian conditioning has been previously shown to be present in hyposerotonergic mice, including Pet $1 \mathrm{KO}$ mice, with a distinctive increase in conditioned fear response phenotype (Dai et al, 2008; Kiyasova et al, 2011). We show here that extinction of fear memory is normal in these mice, a type of learning that is highly dependent on the medial prefrontal cortex (Herry et al, 2010). It seems paradoxical that Pet $1 \mathrm{KO}$ mice show impairment in NORT but intact contextual learning as both tasks are hippocampal dependent. It is likely that the emotional valence of fear conditioning $v s$ the neutral stimulus presented during NORT have a role in this divergence. Memory for emotional information is usually better than memory for neutral information, a phenomenon commonly called emotional enhancement of memory (Phelps, 2004). Emotions can enhance the encoding and consolidation of experiences, likely involving projections from the amygdala to the hippocampus (LaBar and Cabeza, 2006; Phelps, 2004). In Pet1KO mice, serotonergic projections to the amygdala are maintained and stress responses are heightened (data not shown) likely contributing to the enhancement storage of fear memories. Overall, this points the specificity of the cognitive deficits that result from reduced 5-HT transmission and pinpoints to the hippocampal formation as a potential substrate. Visual recognition memory, ie, the ability to distinguish novel from familiar stimuli, is shared across species (Kinnavane et al, 2015; Manns and Eichenbaum, 2009; Squire et al, 2007). Our results are in accordance with previous studies showing that decreasing 5-HT levels, with a hypotryptophan diet, causes impaired memory in visual and verbal learning tasks in healthy volunteers (Riedel et al, 1999; Silber and Schmitt, 2010), and object recognition in rodents (du Jardin et al, 2014; Lieben et al, 2004; Olivier et al, 2008). Interestingly alteration of visual recognition memory is a key symptom of mild cognitive impairment where it has been noted to be a good predictor of Alzheimer's disease (De Anna et al, 2014). Visual memory is also impaired in patients suffering from major depression and posttraumatic stress disorder (Castaneda et al, 2008; Marazziti et al, 2010; Millan et al, 2012). This evidence, together with the results shown in this study, suggest that 5-HT systems are directly involved in normal memory function, specifically in delayed recognition of familiar stimuli.

Serotonergic neurotransmission is very broadly distributed in the brain complicating anatomo-functional correlates. However, genetic approaches are now allowing teasing out more precisely the contribution of different components of the 5-HT systems. Recent studies have focused on the regionselective contribution of 5-HT to anxiety and reward-related 
a
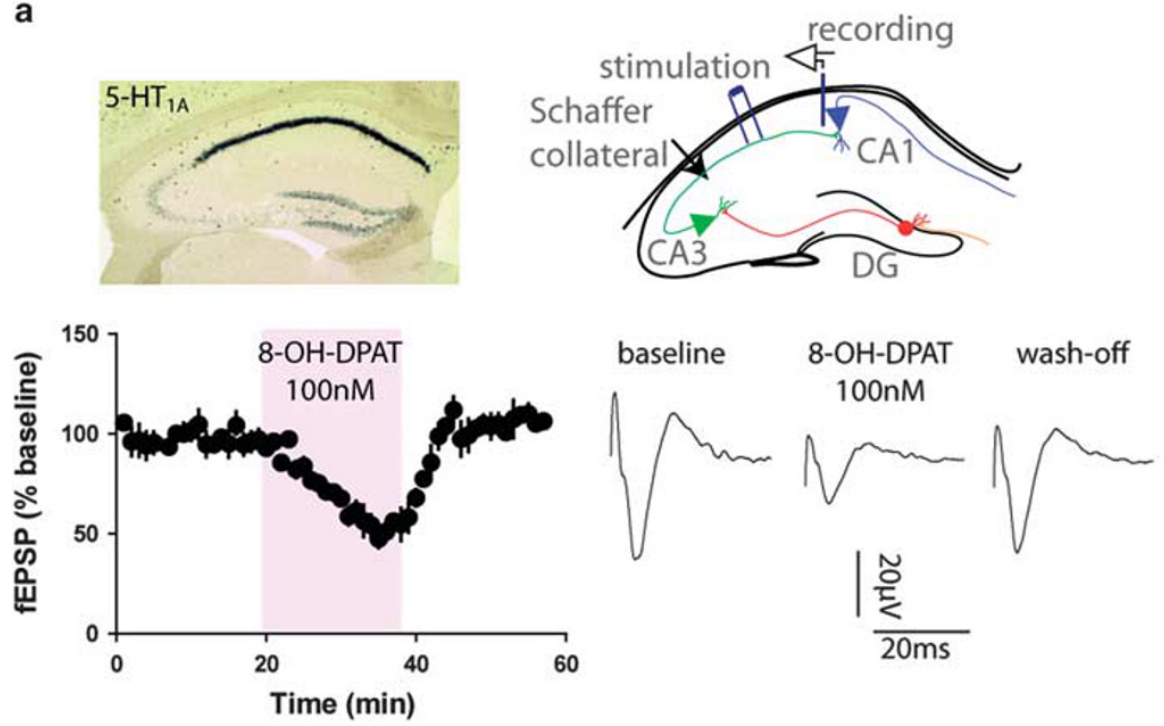

b

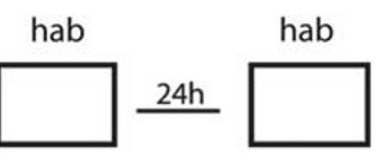

$24 \mathrm{~h}$
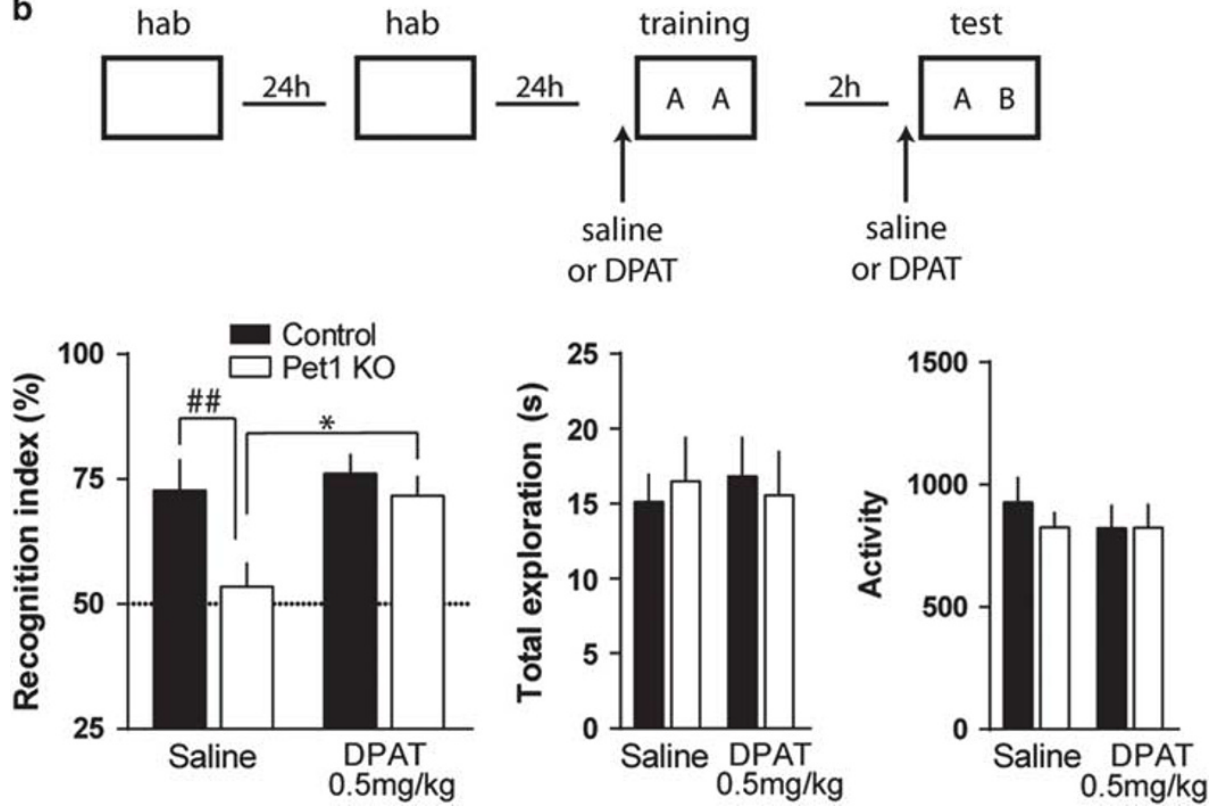

Figure 6 5-HTIA receptors exert inhibitory control over hippocampal CA3 $\rightarrow$ CAI synapse. (a) 5-HTIA mRNA expression was detected using in situ hybridization (blue signal is positive), showing strong expression in stratum pyramidale of the CAI region, where pyramidal neuron cell bodies are located. The effect of the 5-HTIA agonist 8-OH-DPAT was tested on CAI-evoked EPSPs by stimulating CA3 fibers as depicted in the diagram. After a 20-min baseline, 8-OH-DPAT $100 \mathrm{nM}$ was added to the perfusion bath and the amplitude of the EPSPs was recorded. 8-OH-DPAT exerted a strong inhibition of fEPSP amplitude. Representative EPSP traces are shown on the right side. Plot depicts mean \pm SEM $(n=4)$. (b) $8-O H-D P A T(0.5 \mathrm{mg} / \mathrm{kg})$ was injected to control and Pet IKO mice 30 min before training and retention sessions of NORT. Pet I KO injected with saline showed object recognition impairment as compared with control mice $\left(F_{1,50}=6.734,{ }^{\# \#} P<0.01\right.$ control vs Pet I KO in saline treated, Bonferroni posttest, after two-way ANOVA). Treatment with 8-OH-DPAT did not affect the performance of control mice, but it restored preference for the novel object in Pet I KO mice $\left(F_{1.50}=4.50 \mathrm{I}\right.$, *P $<0.05$ saline vs $8-O H$-DPAT in Pet IKO mice, Bonferroni posttest, after two-way ANOVA). Drug treatment did not affect the total amount of time exploring the objects or the locomotor activity during the test. Mice per group were as follows: control: I3 for saline and I3 for DPAT; Pet IKO: I4 for saline and I4 for DPAT. All plots depict mean \pm SEM.

behaviors (Liu et al, 2014; McDevitt et al, 2014; Qi et al, 2014; Teissier et al, 2015). In the present study, we used the chemogenetic tool DREADDS to interrogate the relative contribution of 5-HT innervation to the main brain structures that has been implicated in object recognition, ie, the hippocampus and the entorhinal/perirhinal cortex which receive their 5-HT innervation from the MnR and DR, respectively (Muzerelle et al, 2016). We found that only inactivation of 5-HT neurons in the MnR led to deficits in NORT performance. Furthermore, silencing before training but not before testing is effective in impairing object memory. This provides two main conclusions: (1) that the $\mathrm{MnR}$ is directly linked to the control of object recognition and (2) that the continuous activity of 5-HT neurons in the $\mathrm{MnR}$ is necessary for memory encoding/consolidation but not to retrieve of already formed memories. The former 
conclusion directly adds to our knowledge about the circuits that participate and modulate object recognition memory formation. The MnR has been previously linked with other types of memory function (Babar et al, 2002; Ohmura et al, 2010; Wang et al, 2015), but its direct involvement in object recognition has not been asserted, to the best of our knowledge. Our results showed that pharmaco-genetic inhibition of this subcortical pathway directly affects object recognition in mice.

In the hippocampus, long-term synaptic strengthening in CA3-CA1 pathway requires physiological and biochemicalplastic-changes involving, primarily, glutamate AMPA and NMDA receptors (Neves et al, 2008). 5-HT provides neuromodulatory control over physiological hippocampal circuits by altering homeostatic cell excitability and synaptic strength (Cai et al, 2013; Costa et al, 2011; Dale et al, 2015; Pugliese et al, 1998; Varga et al, 2009). Here we show that constitutive lack of 5-HT, as modeled in Pet1KO mice, results in increased synaptic potentiation, which was difficult to predict based on the expression of diverse 5-HT subtypes in the hippocampus. This 'hyperexcitability' phenotype could result from reduced inhibition of hippocampal circuits that involves two different mechanisms: (i) inhibitory control of pyramidal CA1 neurons by hyperpolarizing 5 -HT1A receptors or (ii) activation of excitatory 5-HT3 receptors expressed primarily on GABAergic interneurons (Costa et al, 2011; Freeman-Daniels et al, 2011; Pugliese et al, 1998; Varga et al, 2009). Although chemogenetic silencing of the MnR 5-HT cells replicate the same memory impairment as observed in Pet1KO, we cannot confirm that this manipulation led to the same enhacement of hippocampal synaptic plasticity. However, a recent report that used simultaneous recordings in the hippocampus and the MnR elegantly showed that firing activity of 5-HT neurons readily inhibits ripple oscillations (Wang et al, 2015). In this context, it is possible that 5-HT deficiency results in an alteration of signal-to-noise ratio in hippocampal neuronal circuits, resulting in excessive synaptic strengthening. LTP is generally viewed as a cellular mechanism mediating memory storage; however, it has been shown that enhanced LTP does not necessarily translates into better memory performance. For example, genetic deletion of synaptic proteins such as PSD-95, IRSp53, and protein tyrosine phosphatase delta or of components of the cAMP signaling cascade all result in a similar phenotype, including impairment in hippocampus-dependent memory and enhanced hippocampal LTP (Kim et al, 2009; Migaud et al, 1998; Pineda et al, 2004; Uetani et al, 2000). Although the mechanisms are not clear, current models support the notion that learning and memory depends on synapsespecific fluctuation in synaptic strength (Takeuchi et al, 2014). In this context, the non-specific strengthening of synapses after subthreshold stimuli may occlude the correct formation of memory engrams. Interestingly, we show here that activation of 5-HT1A receptors with the agonist 8-OHDPAT inhibits CA3-CA1 synaptic input, and pretreatment with this drug is sufficient to rescue NORT memory impairment in 5-HT-deficient mice. From these observations, we conclude that serotonergic inhibitory control over the hippocampal formation is necessary for normal memory function.

In human pathology, altered 5-HT neurotransmission can result from multiple causes that are either inherited or acquired. Genetic variants of 5-HT-related genes have been largely implicated in psychiatric disorders, such as depression or autism (Holmes, 2008; Jacobsen et al, 2012; Scott and Deneris, 2005). In addition, reduced 5-HT transmission can result from several neurodegenerative disorders, such as Parkinson's and Alzheimer's disease (Chen et al, 1996; JavoyAgid et al, 1984; Lai et al, 2002; Qamhawi et al, 2015; Seidel et al, 2015). Because these brain disorders have multiple neuronal targets, it is then difficult to tease apart the specific contribution of a given neuronal system to the observed symptoms. Traditionally, reductions of 5-HT transmission have been linked to the depressive and anxiety-related symptoms and to impulsivity (Heninger et al, 1996; Jacobsen et al, 2012; Winstanley et al, 2004). However, as clearly indicated by our preclinical models, reduced 5-HT transmission has to be considered as a cause of altered declarative memory function. Our study further outlines the fact that similar cognitive defects result from different causes of 5-HT depletion, either constitutive or acquired. Here life-long depletion (Pet1KO mice) or depletion in adulthood (chronic in VMAT2-flox mice or acute by chemogenetic inhibition) all produced defects in novel object recognition, indicating that this is not due to developmental or adaptive effect. Future studies will address key aspects relating 5-HT deficiency, depression, and cognitive performance; the use of preclinical models, where the discrete role of 5-HT in different brain regions can be dissected out, will provide a unique approach to this enterprise (Fernandez and Gaspar, 2012; Mosienko et al, 2015).

\section{FUNDING AND DISCLOSURE}

This study was supported by a grant from the European Community's Seventh Framework Program (FP7/200720139 under grant agreement no. 201714, DEVANX), the Fondation Jerome Lejeune, the Fédération pour la Recherche sur le Cerveau, and the Fondation pour la Recherche Medicale. The authors declare no conflict of interest.

\section{ACKNOWLEDGMENTS}

We thank the IFM imaging and animal platforms, Mr José María González Martín for his help in animal handling and preparation, and Wendy Marcantonio for technical assistance. We also thank Paula Pausinha, Ingrid Bethus, and Helene Marie for comments on the manuscript. We thank the team of $\mathrm{P}$ Gaspar who are part of the Ecole des Neurosciences de Paris (ENP) and the Labex Biopsy.

\section{REFERENCES}

Adell A, Carceller A, Artigas F (1993). In vivo brain dialysis study of the somatodendritic release of serotonin in the Raphe nuclei of the rat: effects of 8-hydroxy-2-(di-n-propylamino)tetralin. J Neurochem 60: 1673-1681.

Babar E, Melik E, Ozgünen T, Polat S (2002). Effects of excitotoxic median raphe lesion on working memory deficits produced by the dorsal hippocampal muscarinic receptor blockade in the inhibitory avoidance in rats. Brain Res Bull 57: 683-688.

Balleine BW, Liljeholm M, Ostlund SB (2009). The integrative function of the basal ganglia in instrumental conditioning. Behav Brain Res 199: 43-52. 
Barnes NM, Sharp T (1999). A review of central 5-HT receptors and their function. Neuropharmacology 38: 1083-1152.

Bielsky IF, Young LJ (2004). Oxytocin, vasopressin, and social recognition in mammals. Peptides 25: 1565-1574.

Buhot MC, Martin S, Segu L (2000). Role of serotonin in memory impairment. Ann Med 32: 210-221.

Cai X, Kallarackal AJ, Kvarta MD, Goluskin S, Gaylor K, Bailey AM et al (2013). Local potentiation of excitatory synapses by serotonin and its alteration in rodent models of depression. Nat Neurosci 16: 464-472.

Castaneda AE, Tuulio-Henriksson A, Marttunen M, Suvisaari J, Lönnqvist J (2008). A review on cognitive impairments in depressive and anxiety disorders with a focus on young adults. $J$ Affect Disord 106: 1-27.

Chen CP, Alder JT, Bowen DM, Esiri MM, McDonald B, Hope T et al (1996). Presynaptic serotonergic markers in communityacquired cases of Alzheimer's disease: correlations with depression and neuroleptic medication. J Neurochem 66: 1592-1598.

Clarke JR, Cammarota M, Gruart A, Izquierdo I, Delgado-García JM (2010). Plastic modifications induced by object recognition memory processing. Proc Natl Acad Sci USA 107: 2652-2657.

Cohen SJ, Munchow AH, Rios LM, Zhang G, Asgeirsdóttir HN, Stackman RWJ (2013). The rodent hippocampus is essential for nonspatial object memory. Curr Biol 23: 1685-1690.

Costa L, Trovato C, Musumeci SA, Catania MV, Ciranna L (2011). 5-HT(1A) and 5-HT(7) receptors differently modulate AMPA receptor-mediated hippocampal synaptic transmission. Hippocampus 22: 790-801.

Dai J-X, Han H-L, Tian M, Cao J, Xiu J-B, Song N-N et al (2008). Enhanced contextual fear memory in central serotonindeficient mice. Proc Natl Acad Sci USA 105: 11981-11986.

Dale E, Pehrson AL, Jeyarajah T, Li Y, Leiser SC, Smagin G et al (2015). Effects of serotonin in the hippocampus: how SSRIs and multimodal antidepressants might regulate pyramidal cell function. CNS Spectr 21: 143-161 1-19.

De Anna F, Felician O, Barbeau E, Mancini J, Didic M, Ceccaldi M (2014). Cognitive changes in mild cognitive impairment patients with impaired visual recognition memory. Neuropsychology 28: 98-105.

du Jardin KG, Jensen JB, Sanchez C, Pehrson AL (2014). Vortioxetine dose-dependently reverses 5-HT depletion-induced deficits in spatial working and object recognition memory: A potential role for 5-HT1A receptor agonism and 5-HT3 receptor antagonism. Eur Neuropsychopharmacol 24: 160-171.

Fernandez SP, Gaspar P (2012). Investigating anxiety and depressive-like phenotypes in genetic mouse models of serotonin depletion. Neuropharmacology 62: 144-154.

Freeman-Daniels E, Beck SG, Kirby LG (2011). Cellular correlates of anxiety in CA1 hippocampal pyramidal cells of 5-HT1A receptor knockout mice. Psychopharmacology (Berl) 213: 453-463.

Geldenhuys WJ, Van der Schyf CJ (2011). Role of serotonin in Alzheimer's disease: a new therapeutic target? CNS Drugs 25: 765-781.

Gruart A, Muñoz MD, Delgado-García JM (2006). Involvement of the CA3-CA1 synapse in the acquisition of associative learning in behaving mice. J Neurosci 26: 1077-1087.

Harmer CJ (2008). Serotonin and emotional processing: does it help explain antidepressant drug action? Neuropharmacology 55: 1023-1028.

Hedge SS, Moy TM, Perry MR, Loeb M, Eglen RM (1994). Evidence for the involvement of 5-hydroxytryptamine 4 receptors in 5-hydroxytryptophan-induced diarrhea in mice. J Pharmacol Exp Ther 271: 741-747.

Hendricks TJ, Fyodorov DV, Wegman LJ, Lelutiu NB, Pehek EA, Yamamoto B et al (2003). Pet-1 ETS gene plays a critical role in 5-HT neuron development and is required for normal anxietylike and aggressive behavior. Neuron 37: 233-247.

Heninger GR, Delgado PL, Charney DS (1996). The revised monoamine theory of depression: a modulatory role for monoamines, based on new findings from monoamine depletion experiments in humans. Pharmacopsychiatry 29: 2-11.

Herry C, Ferraguti F, Singewald N, Letzkus JJ, Ehrlich I, Lüthi A (2010). Neuronal circuits of fear extinction. Eur J Neurosci 31: 599-612.

Hikosaka O, Nakahara H, Rand MK, Sakai K, Lu X, Nakamura K et al (1999). Parallel neural networks for learning sequential procedures. Trends Neurosci 22: 464-471.

Hökfelt T, Fuxe K, Goldstein M (1973). Immunohistochemical localization of aromatic L-amino acid decarboxylase (DOPA decarboxylase) in central dopamine and 5-hydroxytryptamine nerve cell bodies of the rat. Brain Res 53: 175-180.

Holmes A (2008). Genetic variation in cortico-amygdala serotonin function and risk for stress-related disease. Neurosci Biobehav Rev 32: 1293-1314.

Imai H, Steindler DA, Kitai ST (1986). The organization of divergent axonal projections from the midbrain raphe nuclei in the rat. J Comp Neurol 243: 363-380.

Isoda K, Morimoto M, Matsui F, Hasegawa T, Tozawa T, Morioka S et al (2010). Postnatal changes in serotonergic innervation to the hippocampus of methyl-CpG-binding protein 2-null mice. Neuroscience 165: 1254-1260.

Jacobs BL, Azmitia EC (1992). Structure and function of the brain serotonin system. Physiol Rev 72: 165-229.

Jacobsen JPR, Medvedev IO, Caron MG (2012). The 5-HT deficiency theory of depression: perspectives from a naturalistic 5-HT deficiency model, the tryptophan hydroxylase 2Arg439His knockin mouse. Philos Trans R Soc Lond B Biol Sci 367: 2444-2459.

Javoy-Agid F, Ruberg M, Taquet H, Bokobza B, Agid Y, Gaspar P et al (1984). Biochemical neuropathology of Parkinson's disease. Adv Neurol 40: 189-198.

Kim M-H, Choi J, Yang J, Chung W, Kim J-H, Paik SK et al (2009). Enhanced NMDA receptor-mediated synaptic transmission, enhanced long-term potentiation, and impaired learning and memory in mice lacking IRSp53. J Neurosci 29: 1586-1595.

Kinnavane L, Albasser MM, Aggleton JP (2015). Advances in the behavioural testing and network imaging of rodent recognition memory. Behav Brain Res 285: 67-78.

Kish SJ, Tong J, Hornykiewicz O, Rajput A, Chang L-J, Guttman M et al (2008). Preferential loss of serotonin markers in caudate versus putamen in Parkinson's disease. Brain 131: 120-131.

Kiyasova V, Fernandez SP, Laine J, Stankovski L, Muzerelle A, Doly $S$ et al (2011). A genetically defined morphologically and functionally unique subset of 5-HT neurons in the mouse raphe nuclei. J Neurosci 31: 2756-2768.

Kocsis B, Varga V, Dahan L, Sik A (2006). Serotonergic neuron diversity: identification of raphe neurons with discharges timelocked to the hippocampal theta rhythm. Proc Natl Acad Sci USA 103: 1059-1064.

LaBar KS, Cabeza R (2006). Cognitive neuroscience of emotional memory. Nat Rev Neurosci 7: 54-64.

Lai MKP, Tsang SWY, Francis PT, Keene J, Hope T, Esiri MM et al (2002). Postmortem serotoninergic correlates of cognitive decline in Alzheimer's disease. Neuroreport 13: 1175-1178.

Lieben CK, Oorsouw K, van, Deutz NE, Blokland A (2004). Acute tryptophan depletion induced by a gelatin-based mixture impairs object memory but not affective behavior and spatial learning in the rat. Behav Brain Res 151: 53-64.

Liu Z, Zhou J, Li Y, Hu F, Lu Y, Ma M et al (2014). Dorsal raphe neurons signal reward through 5-HT and glutamate. Neuron 81: 1360-1374.

Manns JR, Eichenbaum H (2009). A cognitive map for object memory in the hippocampus. Learn Mem 16: 616-624.

Marazziti D, Consoli G, Picchetti M, Carlini M, Faravelli L (2010). Cognitive impairment in major depression. Eur J Pharmacol 626: 83-86.

McDevitt RA, Tiran-Cappello A, Shen H, Balderas I, Britt JP, Marino RAM et al (2014). Serotonergic versus nonserotonergic 
dorsal raphe projection neurons: differential participation in reward circuitry. Cell Rep 8: 1857-1869.

McQuade R, Sharp T (1997). Functional mapping of dorsal and median raphe 5-hydroxytryptamine pathways in forebrain of the rat using microdialysis. J Neurochem 69: 791-796.

Meneses A (1999). 5-HT system and cognition. Neurosci Biobehav Rev 23: 1111-1125.

Migaud M, Charlesworth P, Dempster M, Webster LC, Watabe AM, Makhinson $\mathrm{M}$ et al (1998). Enhanced long-term potentiation and impaired learning in mice with mutant postsynaptic density-95 protein. Nature 396: 433-439.

Millan MJ, Agid Y, Brüne M, Bullmore ET, Carter CS, Clayton NS et al (2012). Cognitive dysfunction in psychiatric disorders: characteristics, causes and the quest for improved therapy. Nat Rev Drug Discov 11: 141-168.

Mosienko V, Beis D, Pasqualetti M, Waider J, Matthes S, Qadri F et al (2015). Life without brain serotonin: reevaluation of serotonin function with mice deficient in brain serotonin synthesis. Behav Brain Res 277: 78-88.

Muzerelle A, Scotto-Lomassese S, Bernard JF, Soiza-Reilly M, Gaspar P (2016). Conditional anterograde tracing reveals distinct targeting of individual serotonin cell groups (B5-B9) to the forebrain and brainstem. Brain Struct Funct 221: 535-561.

Narboux-Nême N, Sagné C, Doly S, Diaz SL, Martin CBP, Angenard G et al (2011). Severe serotonin depletion after conditional deletion of the vesicular monoamine transporter 2 gene in serotonin neurons: neural and behavioral consequences. Neuropsychopharmacology 36: 2538-2550.

Neves G, Cooke SF, Bliss TVP (2008). Synaptic plasticity, memory and the hippocampus: a neural network approach to causality. Nat Rev Neurosci 9: 65-75.

Ohmura Y, Izumi T, Yamaguchi T, Tsutsui-Kimura I, Yoshida T, Yoshioka M (2010). The serotonergic projection from the median raphe nucleus to the ventral hippocampus is involved in the retrieval of fear memory through the corticotropin-releasing factor type 2 receptor. Neuropsychopharmacology 35: 1271-1278.

Olivier JDA, Jans LAW, Korte-Bouws GAH, Korte SM, Deen PMT, Cools AR et al (2008). Acute tryptophan depletion dose dependently impairs object memory in serotonin transporter knockout rats. Psychopharmacology (Berl) 200: 243-254.

Paxinos G, Franklin KBJ. The Mouse Brain in Stereotaxic Coordinates, 1st edn. Gulf Professional Publishing: Amsterdam; Boston, MA, 2004.

Phelps EA (2004). Human emotion and memory: interactions of the amygdala and hippocampal complex. Curr Opin Neurobiol 14: 198-202.

Pineda VV, Athos JI, Wang H, Celver J, Ippolito D, Boulay G et al (2004). Removal of G(ialpha1) constraints on adenylyl cyclase in the hippocampus enhances LTP and impairs memory formation. Neuron 41: 153-163.

Pugliese AM, Passani MB, Corradetti R (1998). Effect of the selective 5-HT1A receptor antagonist WAY 100635 on the inhibition of e.p.s.ps produced by $5-\mathrm{HT}$ in the CA1 region of rat hippocampal slices. Br J Pharmacol 124: 93-100.

Qamhawi Z, Towey D, Shah B, Pagano G, Seibyl J, Marek K et al (2015). Clinical correlates of raphe serotonergic dysfunction in early Parkinson's disease. Brain 138: 2964-2973.
Qi J, Zhang S, Wang H-L, Wang H, de Jesus Aceves Buendia J, Hoffman AF et al (2014). A glutamatergic reward input from the dorsal raphe to ventral tegmental area dopamine neurons. Nat Commun 5: 5390.

Riedel WJ, Klaassen T, Deutz NE, van Someren A, van Praag HM (1999). Tryptophan depletion in normal volunteers produces selective impairment in memory consolidation. Psychopharmacology (Berl) 141: 362-369.

Rogan SC, Roth BL (2011). Remote control of neuronal signaling. Pharmacol Rev 63: 291-315.

Sachs BD, Ni JR, Caron MG (2015). Brain 5-HT deficiency increases stress vulnerability and impairs antidepressant responses following psychosocial stress. Proc Natl Acad Sci USA 112: 2557-2562.

Schmitt JAJ, Wingen M, Ramaekers JG, Evers EAT, Riedel WJ (2006). Serotonin and human cognitive performance. Curr Pharm Des 12: 2473-2486.

Scott MM, Deneris ES (2005). Making and breaking serotonin neurons and autism. Int J Dev Neurosci 23: 277-285.

Seidel K, Mahlke J, Siswanto S, Krüger R, Heinsen H, Auburger G et al (2015). The brainstem pathologies of Parkinson's disease and dementia with Lewy bodies. Brain Pathol 25: 121-135.

Silber BY, Schmitt JAJ (2010). Effects of tryptophan loading on human cognition, mood, and sleep. Neurosci Biobehav Rev 34: 387-407.

Squire LR, Wixted JT, Clark RE (2007). Recognition memory and the medial temporal lobe: a new perspective. Nat Rev Neurosci 8: $872-883$.

Squire LR, Zola SM (1996). Structure and function of declarative and nondeclarative memory systems. Proc Natl Acad Sci USA 93: 13515-13522.

Takeuchi T, Duszkiewicz AJ, Morris RGM (2014). The synaptic plasticity and memory hypothesis: encoding, storage and persistence. Philos Trans R Soc Lond B Biol Sci 369: 20130288.

Teissier A, Chemiakine A, Inbar B, Bagchi S, Ray RS, Palmiter RD et al (2015). Activity of raphé serotonergic neurons controls emotional behaviors. Cell Rep 13: 1965-1976.

Temudo T, Rios M, Prior C, Carrilho I, Santos M, Maciel P et al (2009). Evaluation of CSF neurotransmitters and folate in 25 patients with Rett disorder and effects of treatment. Brain Dev 31: 46-51.

Uetani N, Kato K, Ogura H, Mizuno K, Kawano K, Mikoshiba K et al (2000). Impaired learning with enhanced hippocampal long-term potentiation in PTPdelta-deficient mice. EMBO $J$ 19: 2775-2785.

Varga V, Losonczy A, Zemelman BV, Borhegyi Z, Nyiri G, Domonkos A et al (2009). Fast synaptic subcortical control of hippocampal circuits. Science 326: 449-453.

Vertes RP, Fortin WJ, Crane AM (1999). Projections of the median raphe nucleus in the rat. J Comp Neurol 407: 555-582.

Wang DV, Yau H-J, Broker CJ, Tsou J-H, Bonci A, Ikemoto S (2015). Mesopontine median raphe regulates hippocampal ripple oscillation and memory consolidation. Nat Neurosci 18: 728-735.

Winstanley CA, Dalley JW, Theobald DEH, Robbins TW (2004). Fractionating impulsivity: contrasting effects of central 5-HT depletion on different measures of impulsive behavior. Neuropsychopharmacology 29: 1331-1343.

Supplementary Information accompanies the paper on the Neuropsychopharmacology website (http://www.nature.com/npp) 